Supporting Information

for

\title{
Pesticide-loaded Nanocarriers from Lignin Sulfonates - A Promising Tool for Sustainable Plant Protection
}

\author{
Sebastian Beckers, ${ }^{a}$ Stefan Peil, ${ }^{\mathrm{a}}$ Frederik R. Wurm ${ }^{\mathrm{a}, \mathrm{b}, *}$ \\ ${ }^{[a]}$ Max-Planck-Institut für Polymerforschung, Ackermannweg 10, 55128 Mainz, Germany. \\ ${ }^{[b]}$ Sustainable Polymer Chemistry Group, MESA + Institute for Nanotechnology, Faculty of \\ Science and Technology, Universiteit Twente, PO Box 217, 7500 AE Enschede, The \\ Netherlands.frederik.wurm@utwente.nl
}

\section{Contents}

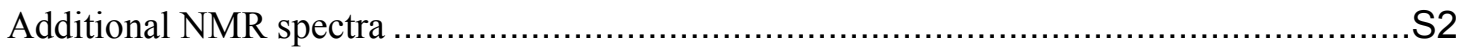

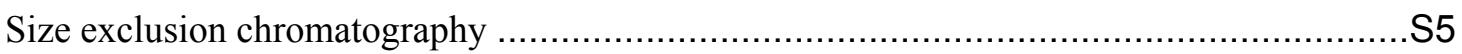

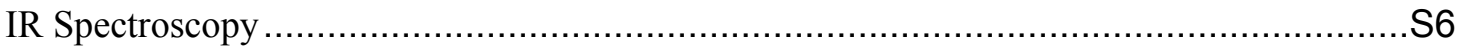

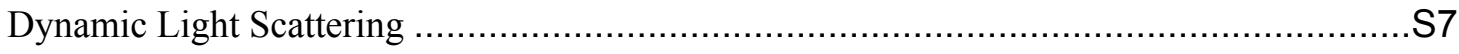

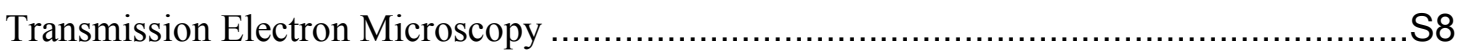

Calibration Curves for Pyraclostrobin and Prothioconazole ............................................... 8

Summary of Methacrylated Lignin's Data …….......................................................... 

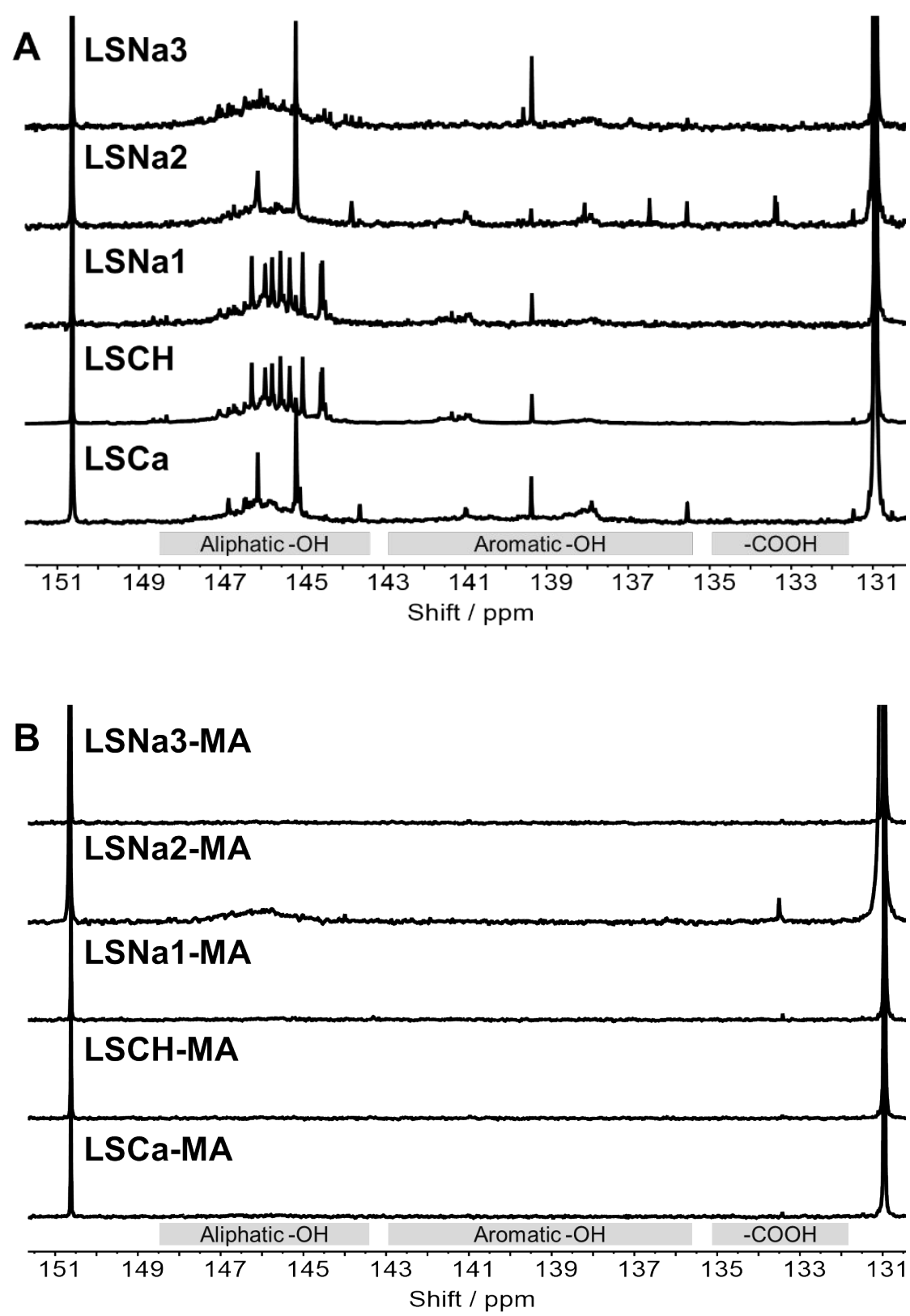

Figure S1: ${ }^{31} \mathrm{P}$ NMR spectra $\left(300 \mathrm{MHz}, 298 \mathrm{~K}, \mathrm{CDCl}_{3} /\right.$ pyridine- $_{5}$ ) of different lignin sulfonates before and after methacrylation. All lignins were derivatized with 2-chloro-4,4,5,5-tetramethyl-1,3,2dioxaphospholane $(153 \mathrm{ppm})$ in the presence of a standard $(133 \mathrm{ppm})$ using the method of Balakshin et al.. By integration, the amount of aromatic and aliphatic hydroxyl groups as well as carboxylic acids were quantified.[14] The lignin sulfonates are abbreviated as follows: $\mathrm{LSCH}=$ Sugared lignin sulfonic acid sodium salt, $\mathrm{LSCa}=$ Sulfonic acid calcium salt, LSNa1-3 = Sulfonic acid sodium salts. Supplier and product number are given in Error! Reference source not found. 

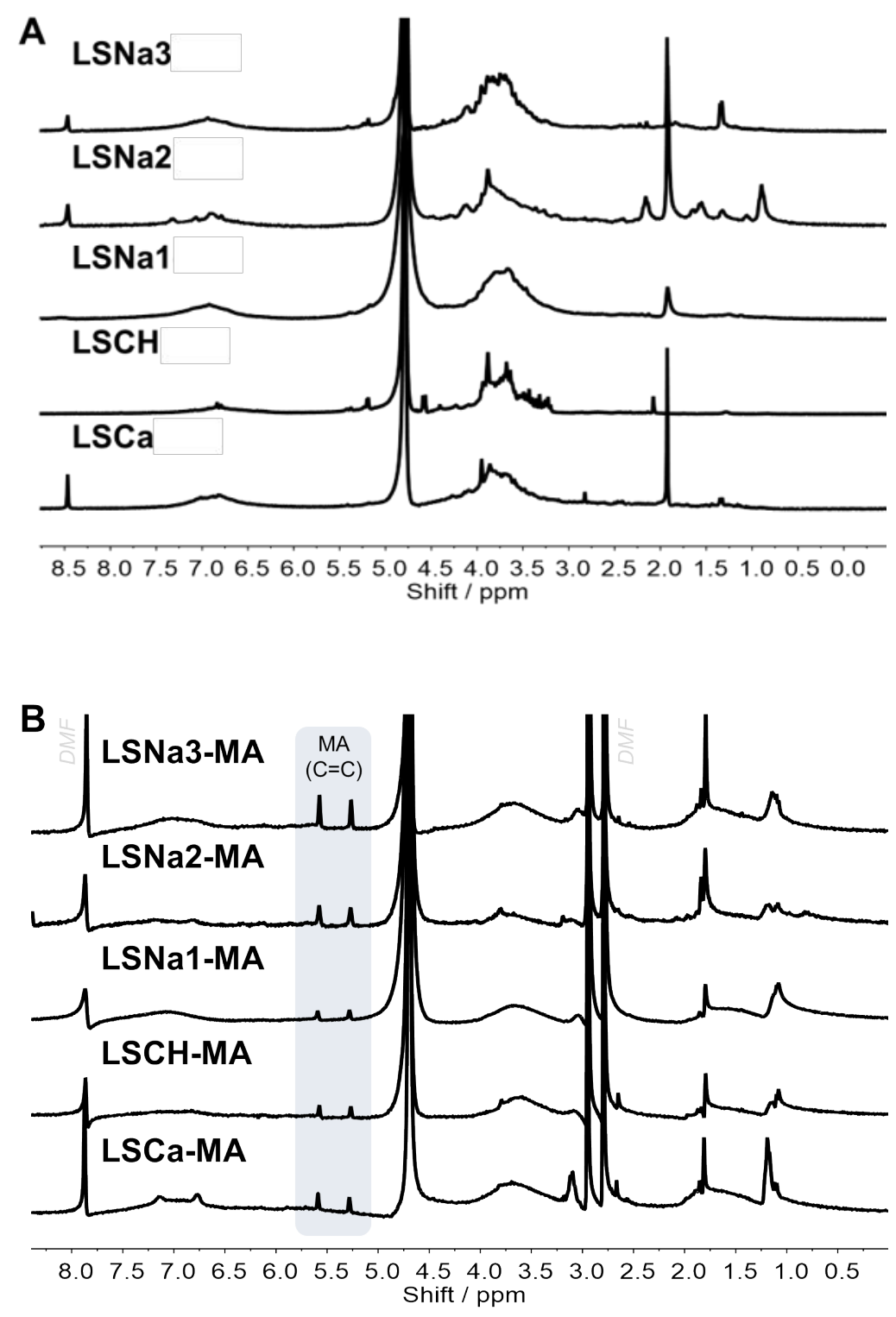

Figure S2: ${ }^{1} \mathrm{H}$ NMR spectra $\left(300 \mathrm{MHz}, 298 \mathrm{~K}, \mathrm{D}_{2} \mathrm{O}\right)$ of different lignin sulfonates before and after methacrylation. The lignin sulfonates are abbreviated as follows: $\mathrm{LSCH}=$ Sugared lignin sulfonic acid sodium salt, LSCa = Sulfonic acid calcium salt, LSNa1-3 = Sulfonic acid sodium salts. Supplier and product number are given in Error! Reference source not found.. 


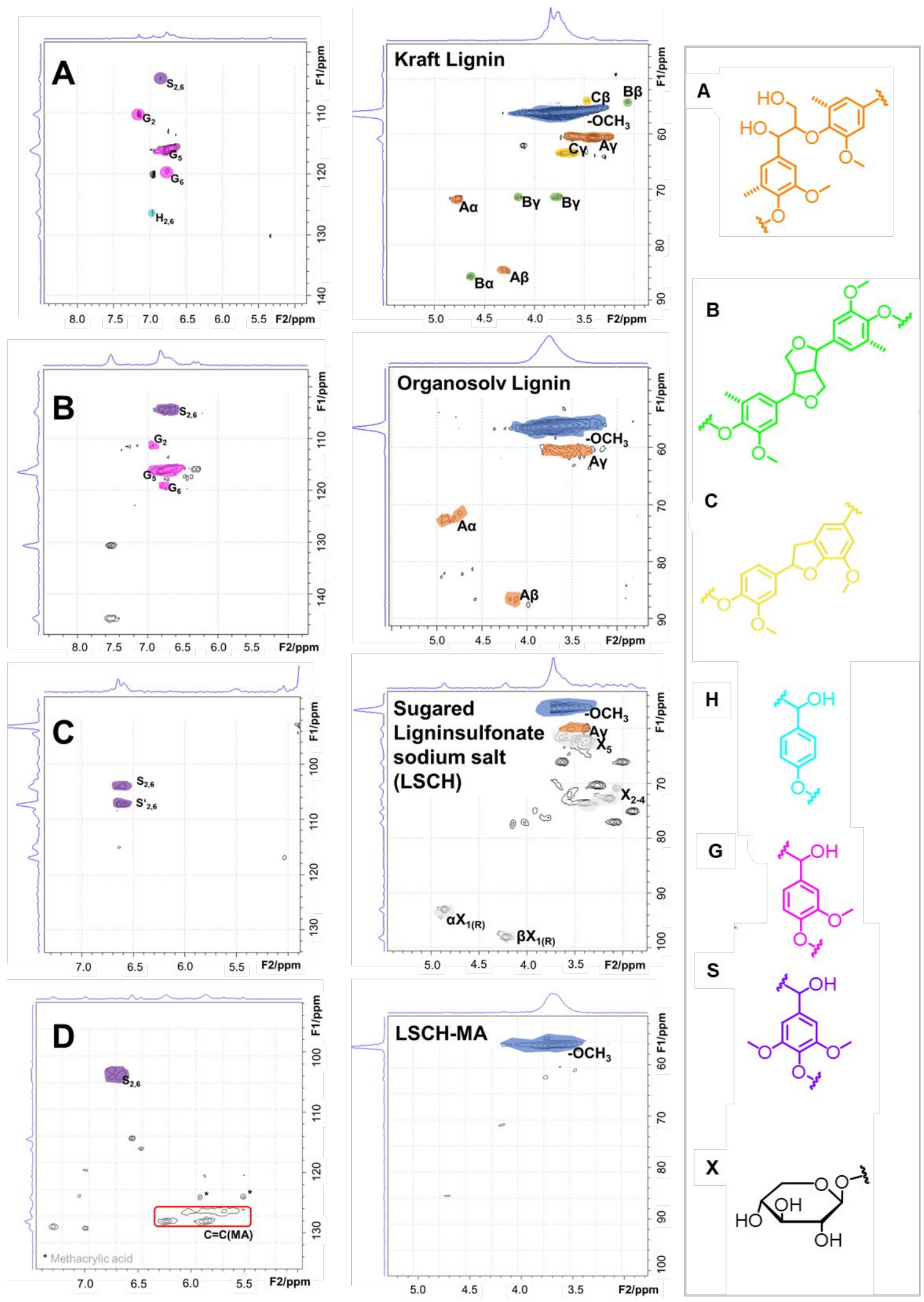

Figure S3: ${ }^{1} \mathrm{H}-{ }^{13} \mathrm{C}-\mathrm{HSQC}$ 2D-NMR (300 MHz, $298 \mathrm{~K}$, DMSO- $d_{6}$ ) spectra of different lignins (A-C) and lignin sulfonate LSCH after methacrylation. The identified binding motives and three phenolic building blocks based on 4-hydroxyphenyl-, guaiacyl- and syringyl alcohol are shown are shown on the right side. 
Size exclusion chromatography:
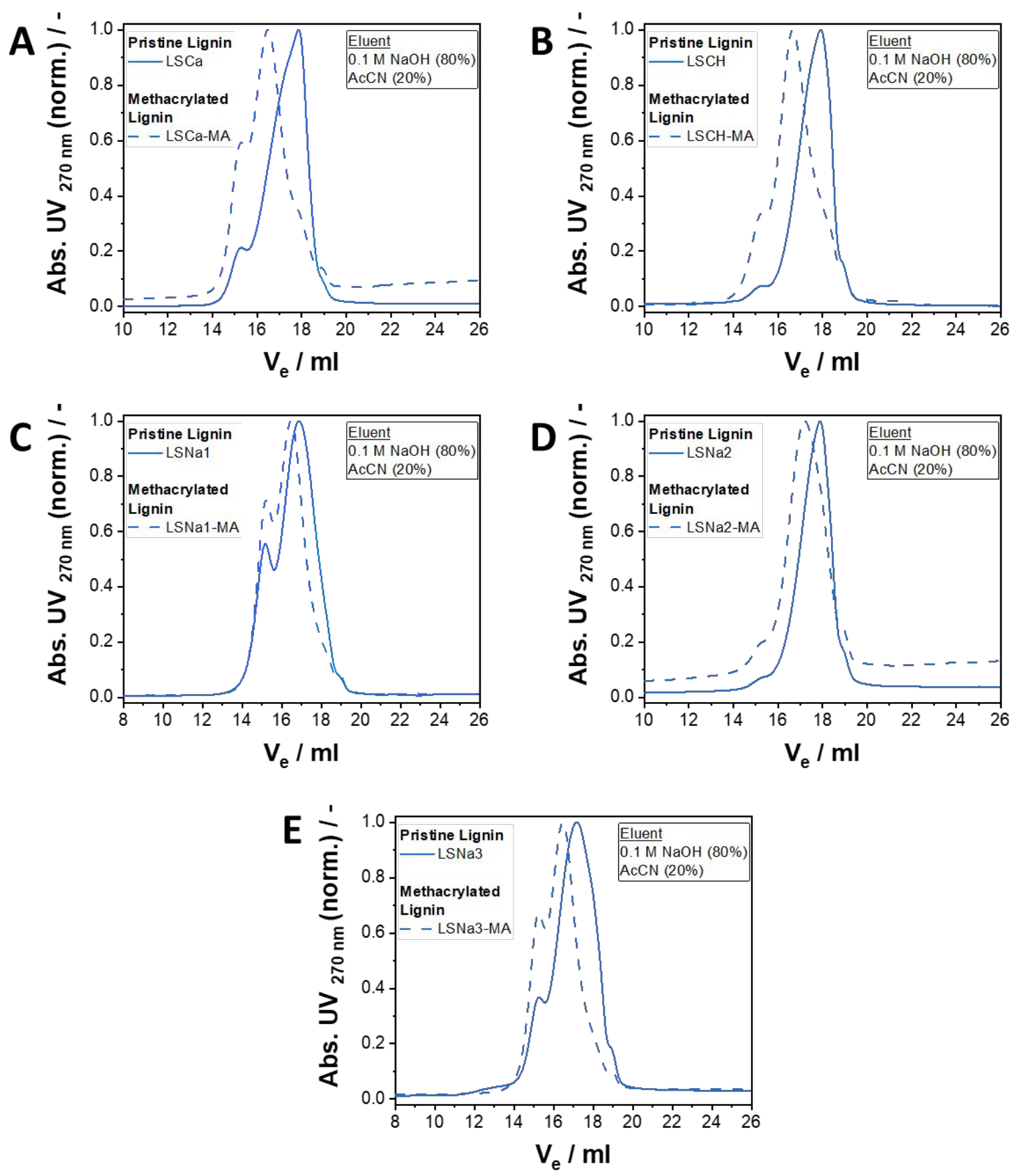

Figure S4: SEC elugrams of different lignin sulfonates using a mixture of $0.1 \mathrm{M} \mathrm{NaOH}$ and acetonitrile as an eluent. 
IR Spectroscopy:

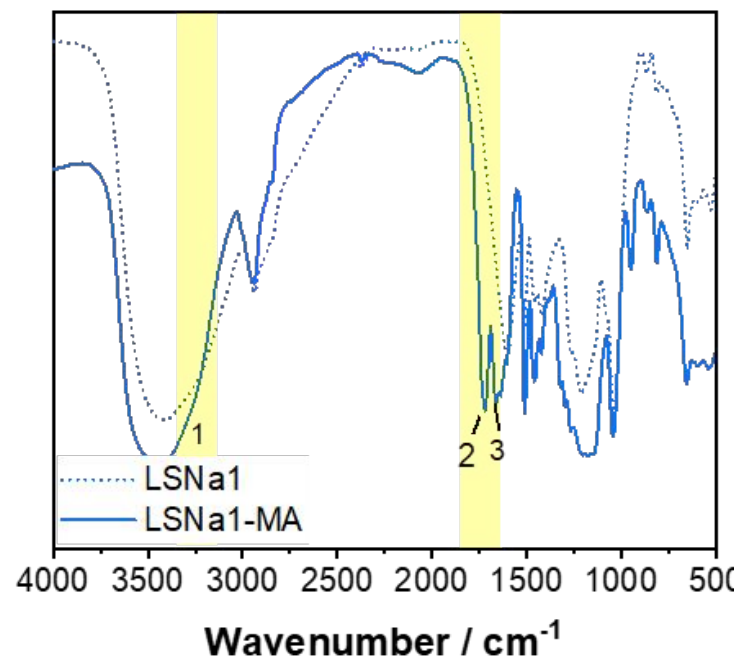

\begin{tabular}{|c|c|c|}
\hline No. & Wavenumber & Band origin \\
\hline 1 & $3214 \mathrm{~cm}^{-1}$ & $\begin{array}{l}\mathrm{O}-\mathrm{H} \text { stretch; Aromatic } \\
\rightarrow \text { Decrease }\end{array}$ \\
\hline 2 & $1736 \mathrm{~cm}^{-1}$ & $\mathrm{C}=\mathrm{O}$ stretch, $\mathrm{MA}$ \\
\hline 3 & $1668 \mathrm{~cm}^{-1}$ & $\mathrm{C}=\mathrm{C}$ stretch, $\mathrm{MA}$ \\
\hline
\end{tabular}

Figure S5: FTIR spectra before and after methacrylation of Organosolv lignin (OL), Kraft lignin (KL) and lignin sulfonate (LSNa1). List of additional signals found after functionalization belonging to the attached methacrylate group. 
Dynamic Light Scattering:
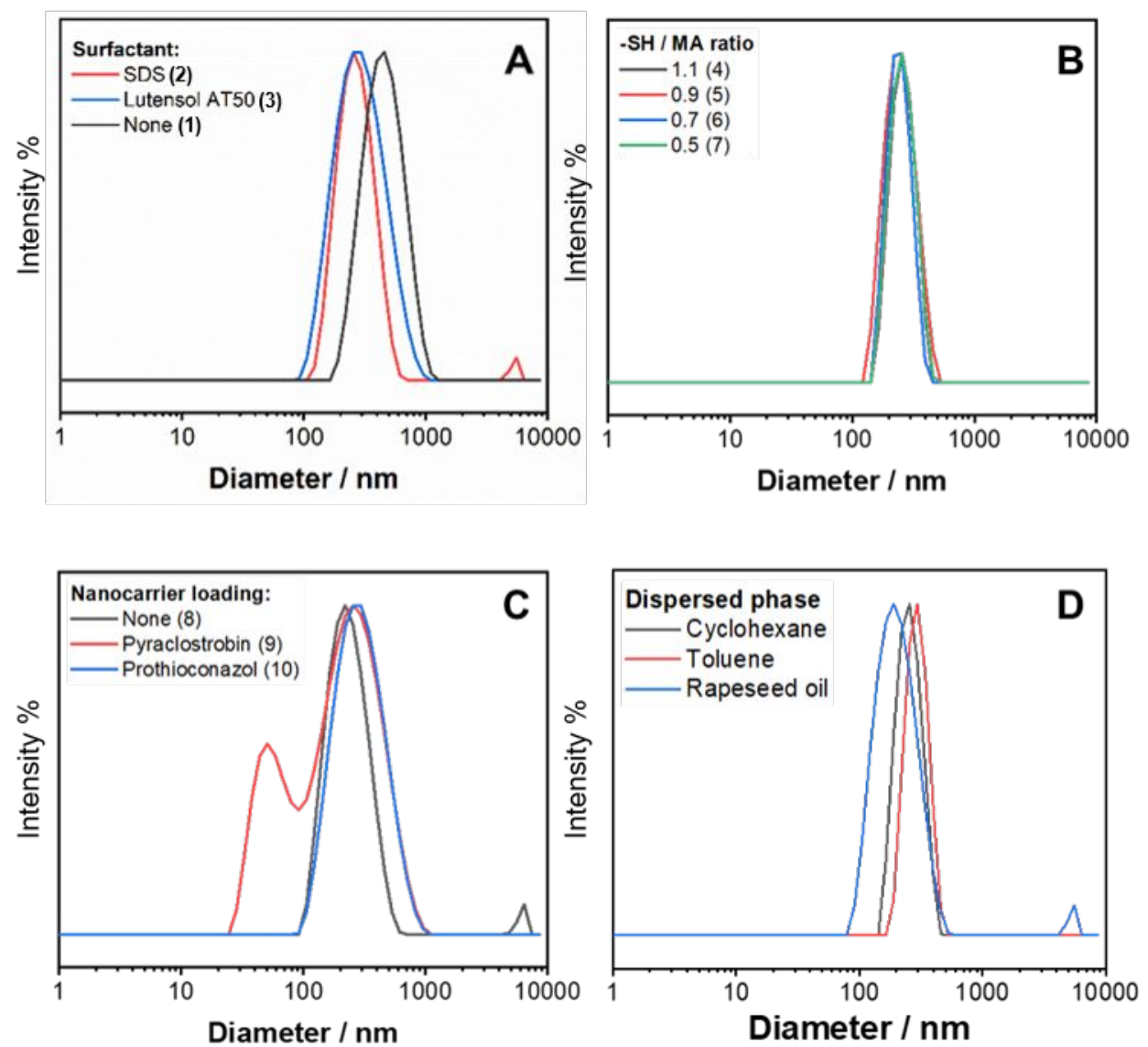

Figure S6: Particle size distributions according to DLS. The nanocarrier dispersions were prepared by interfacial crosslinking of methacrylated lignin sulfonate in a miniemulsion. The effect of surfactant (A), ratio between thiol-crosslinker and methacrylate moieties (B) loading (C) and dispersed phase (D) was investigated.

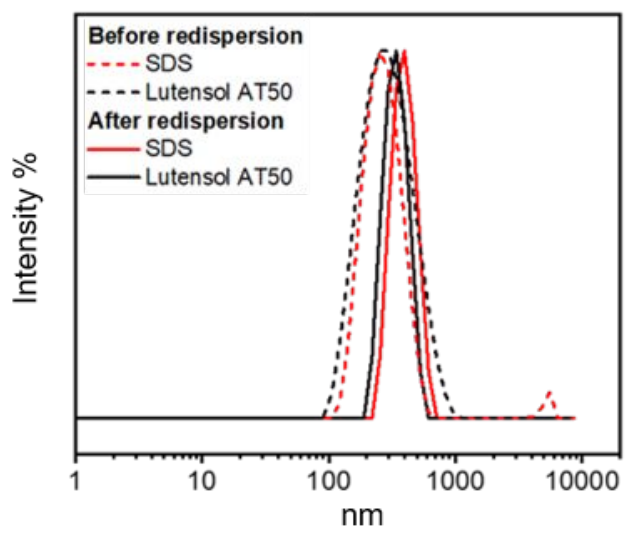

Figure S7: The particle size distributions before and after redispersion in water using SDS or Lutensol At-50 respectively (measured by DLS). 
Transmission Electron Microscopy:
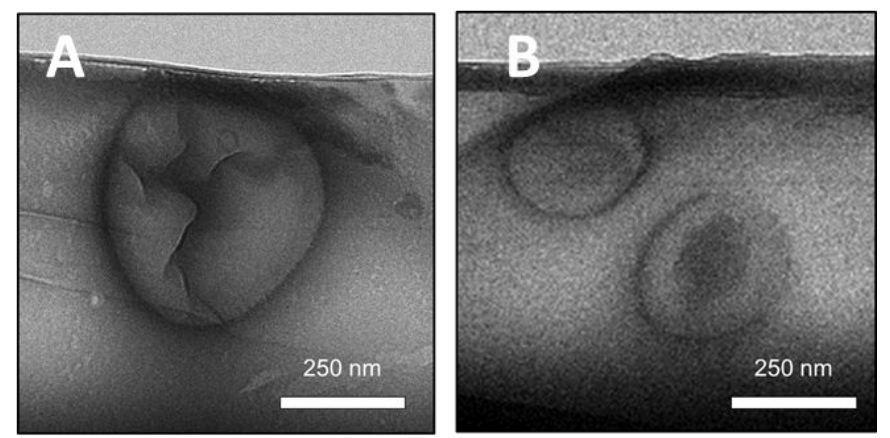

Figure S8: TEM pictures of crosslinked nanocarriers. For preparation cyclohexane was used as a dispersed phase. No cargo was loaded to the nanocarriers (see Table 3 No. 4)

Calibration Curves for Pyraclostrobin and Prothioconazole:
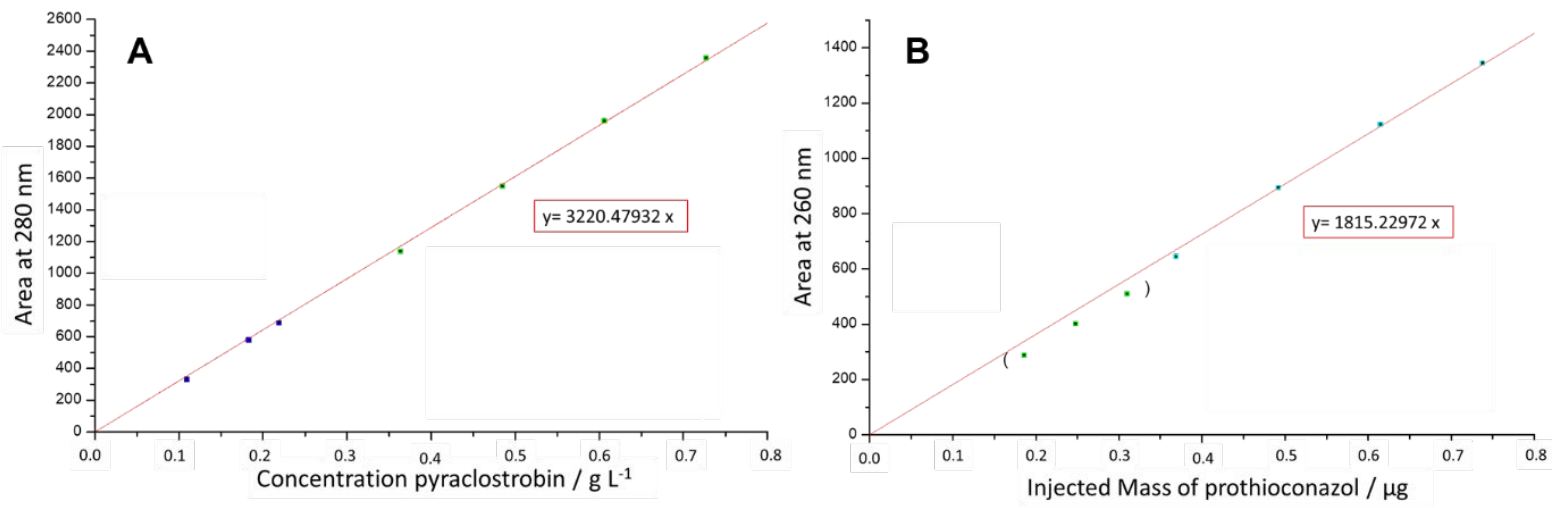

Figure S9: Calibration curves for the quantification of pyraclostrobin (A) and prothioconazole (B) via high pressure liquid chromatography using THF: water/ $0.1 \%$ wt as mobile phase and a TFA-gradient. 
Summary of Methacrylated Lignin's Data:

Table S1: Functional groups found in different methacrylated lignin sulfonates. The amount of hydroxyl groups and the number of methacrylate groups was calculated from ${ }^{31} \mathrm{P}$ NMR using the method of Balakshin et al..[14] The sulfur content was determined by ICP-OES and can be used to estimate the number of sulfonate groups. The weight averaged molecular weight $\left(M_{\mathrm{w}}\right)$ was measured by aqueous SEC vs. polystyrene sodium sulfonate as a reference. The ability to decrease the interfacial tension was measured by spinning drop tensiometry between cyclohexane and a $5 \mathrm{mg} / \mathrm{mL}$ aqueous lignin-MA solution. The interfacial tension between water and cyclohexane is $44.0 \mathrm{Nm} / \mathrm{m}$ without using a surfactant.

\begin{tabular}{l|ccccccc}
\hline No. & $\begin{array}{c}\text { Lignin- } \\
\text { MA }\end{array}$ & $\begin{array}{c}\text { arom OH / } \\
\mathbf{m m o l ~ g}\end{array}$ & $\begin{array}{c}\text { aliph OH } / \\
\mathbf{m m o l ~ g}\end{array}$ & $\begin{array}{c}\mathbf{n}(\mathbf{M A}) / \\
\mathbf{m m o l ~ g}\end{array}$ & $\begin{array}{c}\text { Sulfur } / \\
\mathbf{m m o l ~ g}^{-1}\end{array}$ & $\begin{array}{c}\boldsymbol{M}_{\mathbf{w}} / \\
\mathbf{g ~ m o l}^{-1}\end{array}$ & $\begin{array}{c}\text { Interfacial tension / } \\
\mathbf{~ m m ~ m}^{-1}\end{array}$ \\
\hline $\mathbf{1}$ & LSCH & $0.36 \pm 0.2$ & $1.83 \pm 0.1$ & $18.1 \pm 0.1$ & $1.64 \pm 0.2$ & $3.0 \cdot 10^{4}$ & $12.5 \pm 0.3$ \\
$\mathbf{2}$ & LSCa & $0.25 \pm 0.03$ & $0.54 \pm 0.03$ & $12.0 \pm 0.1$ & $2.70 \pm 0.1$ & $5.5 \cdot 10^{3}$ & $12.2 \pm 0.3$ \\
$\mathbf{3}$ & LSNa1 & n.d. & $0.57 \pm 0.02$ & $12.7 \pm 0.2$ & $1.63 \pm 0.1$ & $1.2 \cdot 10^{4}$ & $6.6 \pm 0.4$ \\
$\mathbf{4}$ & LSNa2 & $0.61 \pm 0.03$ & $1.65 \pm 0.02$ & $5.8 \pm 0.2$ & $1.95 \pm 0.1$ & $5.1 \cdot 10^{3}$ & $14.5 \pm 0.3$ \\
$\mathbf{5}$ & LSNa3 & $0.45 \pm 0.03$ & $2.00 \pm 0.2$ & $17.9 \pm 0.3$ & $1.93 \pm 0.2$ & $1.5 \cdot 10^{4}$ & $12.8 \pm 0.6$ \\
\hline
\end{tabular}

